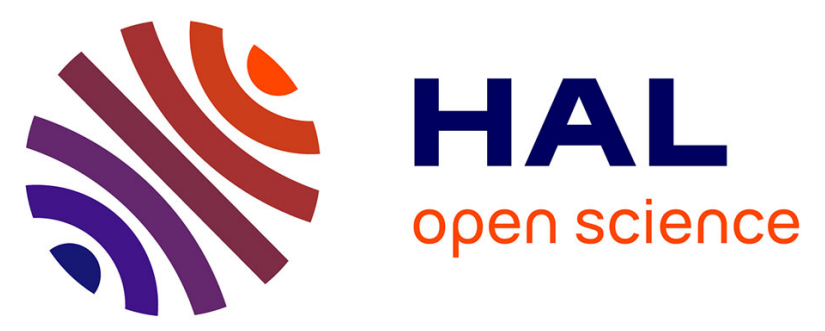

\title{
An efficient control strategy for the hybrid wind-battery system to improve battery performance and lifetime
}

Mehrdad Gholami, Majid Mehrasa, Reza Razi, Ahmad Hably, Seddik Bacha, Antoine Labbone

\section{- To cite this version:}

Mehrdad Gholami, Majid Mehrasa, Reza Razi, Ahmad Hably, Seddik Bacha, et al.. An efficient control strategy for the hybrid wind-battery system to improve battery performance and lifetime. 47th Annual Conference of the IEEE Industrial Electronics Society (IES), Oct 2021, Toronto (virtual), Canada. hal-03410200

\author{
HAL Id: hal-03410200 \\ https://hal.science/hal-03410200
}

Submitted on 31 Oct 2021

HAL is a multi-disciplinary open access archive for the deposit and dissemination of scientific research documents, whether they are published or not. The documents may come from teaching and research institutions in France or abroad, or from public or private research centers.
L'archive ouverte pluridisciplinaire HAL, est destinée au dépôt et à la diffusion de documents scientifiques de niveau recherche, publiés ou non, émanant des établissements d'enseignement et de recherche français ou étrangers, des laboratoires publics ou privés. 


\title{
An efficient control strategy for the hybrid wind-battery system to improve battery performance and lifetime
}

\author{
Mehrdad Gholami ${ }^{1,2}$, Majid Mehrasa ${ }^{1}$, Reza Razi $^{4}$, Ahmad Hably $^{4}$, Seddik Bacha ${ }^{1,3}$, and Antoine Labbone ${ }^{1}$ \\ ${ }^{1}$ Univ. Grenoble Alpes, CNRS, Grenoble INP*, G2Elab, 38000 Grenoble, France \\ ${ }^{2}$ Faculty of engineering, University of Kurdistan, Sanandaj, Iran \\ ${ }^{3}$ SuperGrid Institute, Rue de Cyprian 69100 Villeurbanne, France \\ ${ }^{4}$ Univ. Grenoble Alpes, CNRS, Grenoble INP*, GIPSA-Lab, 38000 Grenoble, France \\ $1,4 *$ Institute of Engineering Univ. Grenoble Alpes \\ 1,2,3,4 $\{$ mehrdad.gholami,majid.mehrasa, seddik.bacha, Antoine.Labonne, reza.razi, ahmad.hably\} @ grenoble-inp.fr
}

\begin{abstract}
The main challenge in hybrid wind-battery systems is the battery cost including investment and replacement. Thus, numerous studies have been conducted on cost minimization. Previous studies often focused on the battery sizing, while the battery performance has also the significant effect on the battery replacement and in turn battery cost. In this paper, a new approach is proposed to improve the battery performance and lifetime. We proposed an extended two-set battery model with new scenarios and formulation to achieve a balance between batteries and managing their power during prediction error. In this model, shallow charge/discharge cycles are eliminated, and batteries experience complete cycles. Furthermore, the battery availability is increased. The simulation results for a case study are presented and the results show the effectiveness of the proposed approach in comparison of conventional models.

Index Terms-Wind power, battery storage, power dispatching, power fluctuation
\end{abstract}

\section{INTRODUCTION}

Renewable energy resources (RERs) introduce variety of advantages such as reducing the dependency to fuel-based resource and increasing the reliability of power systems with availability of distributed generation [1]. However, intermittent and stochastic nature of their generation contributes new challenges to power systems [2], [3]. Energy management using load-generation coordination could be one of the solutions for small micro-grids where techno-economic issues tradeoff can be easily performed [4], [5]. In addition, intermittent renewable generation can be covered by spinning reserve in power systems to some extent. The main challenges arise for high penetration of RERs where it is expected to act like traditional generation units. In fact, they should provide dispatch-able and controllable power to participate in power market and voltage-frequency control programs, respectively [6]-[9]. In the case of power market, which is the scope of this paper, the large generation units penalized for deviations from scheduled power according to up-down regulating prices. Participating in day-ahead power market with having constant power in on-hour intervals is usually defined as dispatching capability for hybrid Battery-Wind systems [10]. Power mismatching is originated from wind speed fluctuation and forecasting error. Although the spatial smoothing reduces the wind power fluctuations, the output power has fluctuations in the range of more than 10 minutes [11]. One of the most popular solutions to remedy the fluctuations and prediction errors is using energy storages specially battery energy storage systems (BESSs) [12]-[16]. The BESSs can compensate surplus and shortage power according to the wind power profile and the scheduled power. Meanwhile, the high cost of BESSs is the main concern for wind-farm owner to use them. Therefore, cost minimization of the BESSs can be more valuable to extend the hybrid systems. The BESSs cost depends on the required capacity (investment cost) and the lifetime (replacement costs). Hence, there are two categories which should be optimized; battery sizing and operation management. The battery capacity depends on the several items such as fluctuation level, perdition error, dispatching strategy, operation strategy. Most of previous studies are focused on the battery sizing and optimizing battery capacity [12], [13], [17]. On the other hand, the lifetime depends on the operation conditions including charge/discharge rate, depth of discharge and the number of complete/shallow cycles. Due to the high fluctuations in wind power, battery experiences a large number of shallow charge/discharge cycles which not only reduces the battery life time but also needs complex formulation to calculate the life time. In this paper, to avoid shallow cycles, we focused on two-set battery model [18]. We extended the two-set model with new algorithm and scenarios to achieve balance condition and managing charge discharge cycles. The results are compared with one battery set model to verify the effectiveness of this method. The rest of the paper is organized as follows. In Section II, a background of the system model is introduced. Then, in Section III, the proposed model is presented. In Section IV, the simulation results for a case study are shown. Finally, Section V is devoted to the conclusions. 


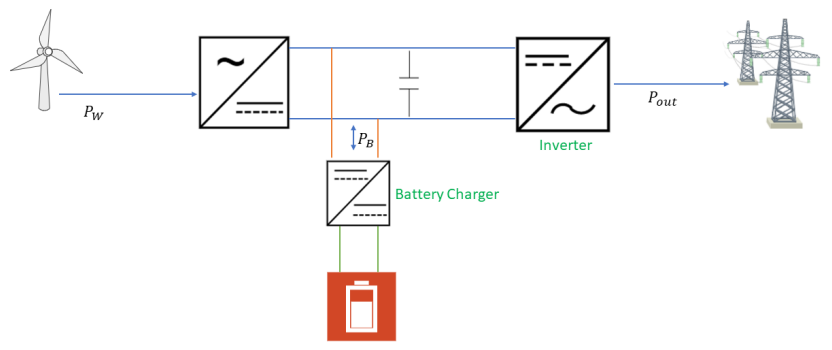

Fig. 1. Hybrid wind-battery system; one-set battery model.

\section{SYSTEM MODEL: BACKGROUND}

A hybrid Battery-Wind system is shown in Fig. 1. The hybrid system is supposed to participate in power market and delivering constant power in time intervals (one-hour intervals). Although wind power systems can announce the average power over one hour as the dispatched power, there will be some deviations due to wind speed fluctuations and prediction error which leads to penalization. This power mismatch can be covered by the BESS, so that the battery is charged during excess power and it is discharged at the time of shortage. The scheduled power is usually defined based on the sliding average of forecasted wind power over one-hour intervals.

$$
\begin{aligned}
& P_{S}\left(t_{i}\right)=\frac{1}{\Delta t} \int_{t_{i}-T / 2}^{t_{i}+T / 2} P_{W}^{f}(t) d t, \\
& P_{S}(t)=P_{S}\left(t_{i}\right) \quad \forall: t_{i}-T / 2<t<t_{i}+T / 2
\end{aligned}
$$

Where $P_{S}$ and $P_{W}^{f}(t)$ are the scheduled power and the forecasted wind power, respectively. T is the length of commitment interval, which is one-hour in this paper. The power mismatch is defined as below:

$$
P_{m}(t)=P_{W}(t)-P_{S}(t)
$$

In which $P_{m}(t)$ and $P_{W}(t)$ are the mismatch power and the wind power. Participating in power market and having constant power over time intervals needs to compensate this mismatch power. The BESS can provide this power to have dispatchable wind power. So, the battery must deliver the mismatch power.

$$
P_{B}(t)=P_{m}(t)
$$

The energy profile and the state of charge (SOC) of battery can be obtained by integrating the power profile:

$E_{B}(t)=E_{B}(0)+$

$\int_{0}^{t} \frac{1}{2} *\left[\eta_{C}\left(1+\operatorname{sign}\left(P_{B}(t)\right)+\eta_{D}\left(1-\operatorname{sign}\left(P_{B}(t)\right)\right] P_{B}(t) d t\right.\right.$

$S O C(t)=\frac{E_{B}(t)}{E_{r}}$

In which $\eta_{C}$ and $\eta_{D}$ are the charge and discharge efficiency and $E_{r}$ is the rated capacity of battery. The required energy capacities can be obtained based on the energy profiles over a long-term period. The required energy capacity $\left(E_{B}^{r}\right)$ is defined according to the maximum energy level in the longterm profile.

$$
E_{B}^{r}=\underbrace{E_{\max }}_{\text {Long-term }}
$$

Due to fast fluctuation of wind power, the battery experiences the fast charge/ discharge cycles. Therefore, the battery experiences shallow cycles rather than complete ones. In this paper, in order to eliminate incomplete cycles and improve battery performance, the approach of two-sets battery model is used which is described in next section.

\section{PROPOSED MODEL}

Non-uniform charge/discharge and shallow cycles is one of the serious challenges of batteries in renewable usage which leads to reduce battery throughput and battery lifetime. In this paper, to avoid shallow cycles, two-set battery model is used to have complete charge/discharge cycles. This strategy can improve the battery performance and reduce the replacement cost compare to one-set battery model. In this paper, a model of two-set model is developed, taking into account the conditions of non-availability of batteries and forecast error. Also, a new scenario for power management has been proposed in order to create coordination and balance between the energy levels of the batteries and to ensure deep consecutive cycles. The general approach is to inject the constant power into the grid at one-hour intervals based on wind power forecasts. As mentioned earlier, fluctuations and prediction errors must be compensated by the battery. On the other hand, batteries have limited capacity and SOC, so the injection of constant power is subject to the availability of batteries, which means that the batteries have the ability to charge or discharge. If the batteries are not available, it is not possible to inject constant power into the grid and the fluctuated power must be injected into the grid. Therefore, the wind power must be managed by the inverter and the battery charger. To ensure this, the voltage of DC link must be kept constant. When the batteries are available, the voltage stabilization of DC link is done by the battery charger and the inverter works in the constant power mode, and in times of unavailability, the voltage stabilization will be the responsibility of the inverter, so the inverter control mode will change. In the following, the performance of each system component will be described.

\section{A. Battery Management System (BMS)}

The extended two-set battery topology is shown in Fig. 2. In this case, the status of batteries must be in contrast, when the first one is discharged the second on must be charged and vice versa.

The main idea in this model is providing complete cycles for both battery sets, so each battery must get to full level; completely discharged $\left(S o C=S O C_{\min }\right)$, or charged $\left(S o C=S o C_{\max }\right)$. Sometimes, due to the prediction error, the positive and negative power profiles will not be the same, so, the batteries do not reach the full level at the same time. In this case, one of the batteries reaches the full level sooner. In order to maintain balance and have complete cycles, the battery that has reached the full level must wait for the second battery, then change the charge or discharge status of both batteries at the same time. Otherwise, there will be an inconsistency and 


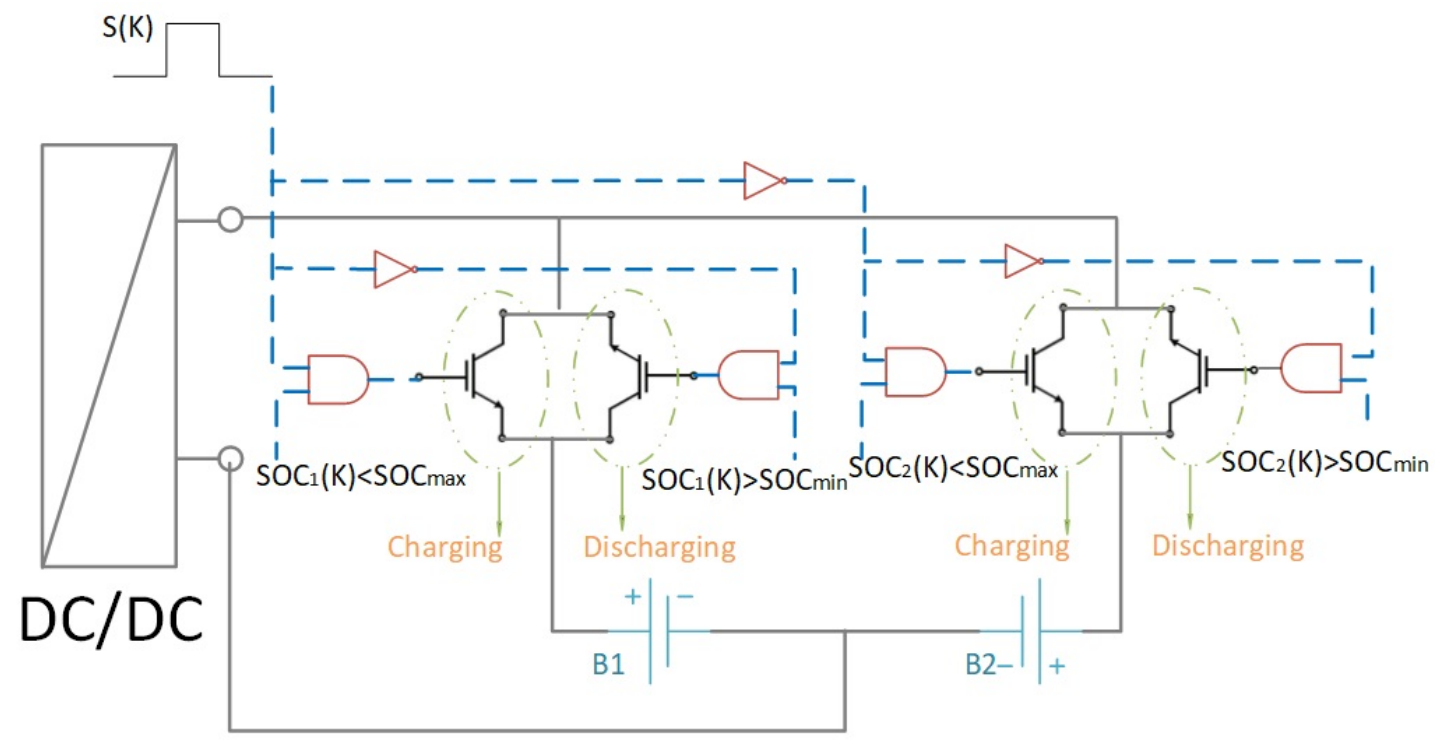

Fig. 2. The extended two-set battery topology.

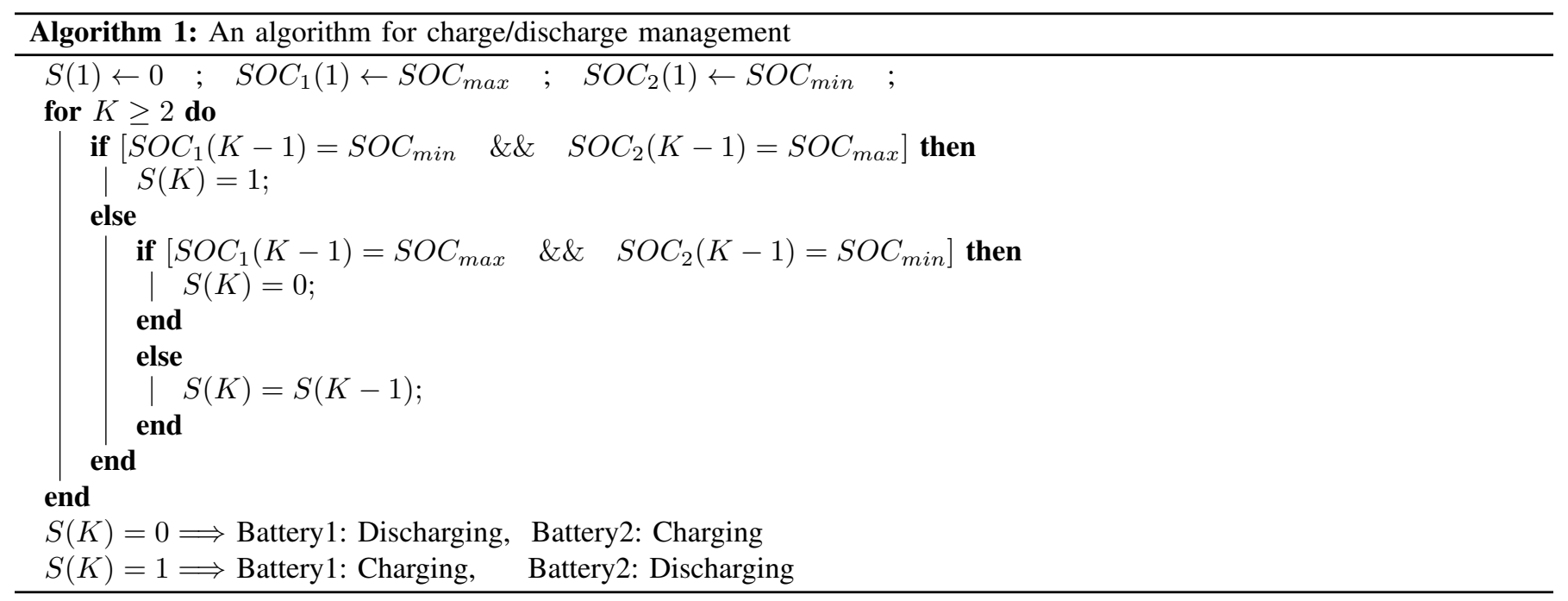

the batteries will be subject to incomplete cycles. To ensure this plan, the algorithm 1 is proposed.

In which, The $S(K)$ is the switching function and depends on the SoCs of both battery sets. This signal determines which battery is charged and which one is discharged at any given time. When $S(K)=0$, battery 1 is discharged and battery 2 is charged, and when $S(K)=1$, battery 1 is charged and battery 2 is discharged.

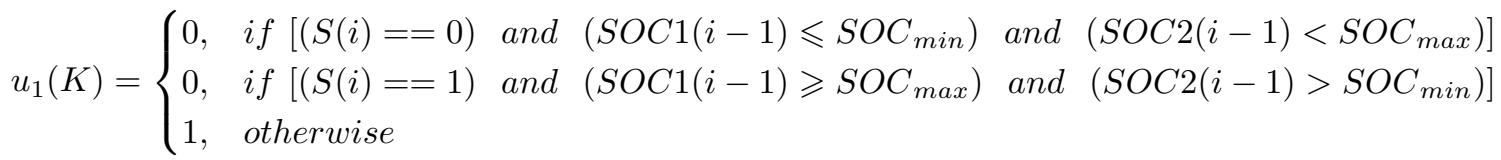

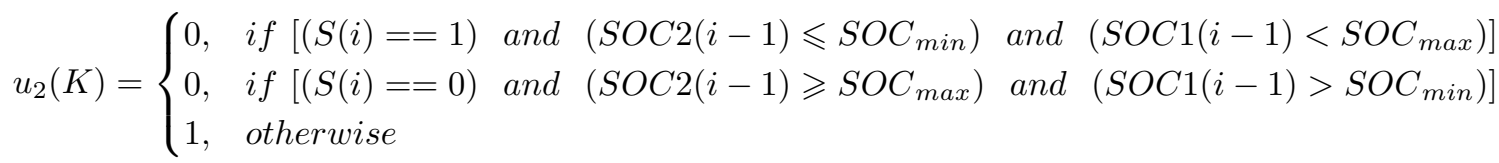

In the proposed model, either both batteries are always available, or at least one of them is available. According to the 
scenario presented for managing the charge and discharge of batteries in Algorithm 1, there will never be a simultaneous unavailability of both batteries. The only condition that can occur is the inaccessibility of one of the batteries. For example, when the first battery has reached the full charge (or discharge) level and the second battery has not yet reached the full discharge (or charge) level. In this case, the first battery will not be available until the second battery reaches the full discharge (or charge) level. This condition may also happen for battery 2. Overall, there are 4 cases in which batteries may not be available. The availability of two battery can be defined as a two-value function $(U(K))$, a value of zero means no access and a value of one means availability(6).
Now, the SOC of the batteries can be obtained based on the availability of each battery and mismatch power profile as (7). The mismatch power is consumed as two part; positive and negative profiles $\left(P_{M i s_{-} P}, P_{M i s_{-} N}\right)$ which are considered for charge and discharge powers, respectively.

Inaccessibility of each battery occurs in one charge mode and one discharge mode. Therefore, from the point of view of the battery charger, there are four modes for not accessing the batteries, two modes for not accessing the charge and two modes for the discharge. The access signal for battery charger is defined as (8).

According to availability signals and the status of the power of battery charger and inverter, the control mode for each part is defined.

$$
\begin{aligned}
& S O C_{1}(K+1)=S O C_{1}(K)+\frac{\Delta t}{E_{B}^{r}}\left[\eta_{C} * P_{M i s_{-} P}(K) * S(K)+\eta_{D} * P_{M i s_{-} N}(K) *(1-S(K))\right] * u_{1}(K) \\
& S O C_{2}(K+1)=S O C_{2}(K)+\frac{\Delta t}{E_{B}^{r}}\left[\eta_{C} * P_{M i_{-} P}(K) *(1-S(K))+\eta_{D} * P_{M i s_{-} N}(K) * S(K)\right] * u_{2}(K)
\end{aligned}
$$

$$
\begin{aligned}
A_{C h}(K) & =\left\{\begin{array}{lll}
0, & \text { if }\left[\left(S O C 1(i-1)==S O C_{\max }\right)\right. & \text { and } \left.\left(S O C 2(i-1)>S O C_{\min }\right)\right] \\
0, & \text { if }\left[\left(S O C 2(i-1)==S O C_{\min }\right)\right. & \text { and } \left.\left(S O C 1(i-1)<S O C_{\max }\right)\right] \\
1, & \text { otherwise }
\end{array}\right. \\
A_{\text {Disch }}(K) & =\left\{\begin{array}{lll}
0, & \text { if }\left[\left(S O C 1(i-1)==S O C_{\min }\right)\right. & \text { and } \left.\left(S O C 2(i-1)<S O C_{\max }\right)\right] \\
0, & \text { if }\left[\left(S O C 2(i-1)==S O C_{\max }\right)\right. & \text { and } \left.\left(S O C 1(i-1)>S O C_{\min }\right)\right] \\
1, & \text { otherwise }
\end{array}\right.
\end{aligned}
$$

$$
\text { Battery charger mode }(K))=\left\{\begin{array}{l}
\text { Blocked, if }\left(P_{c h}(K)<0 \text { and } A_{C h}(K)=0\right) \\
\text { Blocked, if }\left(P_{c h}(K)>0 \text { and } A_{D i s c h}(K)=0\right) \\
\text { Blocked, if }\left(A_{C h}(K) \neq 0 \text { and } A_{D i s c h}(K) \neq 0\right) \\
\text { Active if }\left(A_{C h}(K)=0 \text { and } P_{\text {out }}(K)<P_{D i s p}(K)\right) \\
\text { Active if }\left(A_{D i s c h}(K)=0, P_{\text {out }}(K)<P_{D i s p}(K)\right)
\end{array}\right.
$$

\section{B. Battery Charger Control Mode}

When the battery charger is active, the control mode is maintaining constant DC-link voltage. But in the case of unavailability of batteries, its operation will be blocked. Therefore, the operation of battery charger is defined as (9). In which $P_{c h}(K), P_{D i s p}(K)$ and $P_{\text {out }}(K)$ are the battery charger power, dispatched power and output power injected into the grid at interval $\mathrm{K}$, respectively. As can be seen, the battery charger is activated in three times, the first is when both batteries are available. But the second and third times are related to when one of the charge (or discharge) modes of batteries is not available and the battery charger has stopped. During these times, the output power status should always be checked relative to the dispatching power. If the condition for discharge or (charge) is provided, the battery charger will be reactivated. Assume that the charging mode is not available $\left(A_{C h}(K)=0\right)$, and the battery charger is deactivated and the inverter has gone into the voltage control mode. In this case the output power is greater than the dispatching power, but as soon as the output power is less than the dispatching power, since the discharge mode of the batteries is available, the battery charger is activated and the inverter returns to the constant power mode. When the battery charger goes into the stop mode, the inverter control mode must change, so for coordination, a signal (BC) is sent from the battery charger to the inverter, which is defined as follows.

$$
B C= \begin{cases}0, & \text { Blocked } \\ 1, & \text { Active }\end{cases}
$$




\section{Inverter Control Mode}

The basic control mode for the inverter is constant power. But in the case of blocking the battery charger, its control mode changes to maintain constant DC-link voltage. The operation of inverter is defined as bellow:

$$
\text { Inverter control mode }(K): \begin{cases}\text { ConstantDC-linkvoltage, } & B C=0 \\ \text { Constantpowermode, } & B C=1\end{cases}
$$

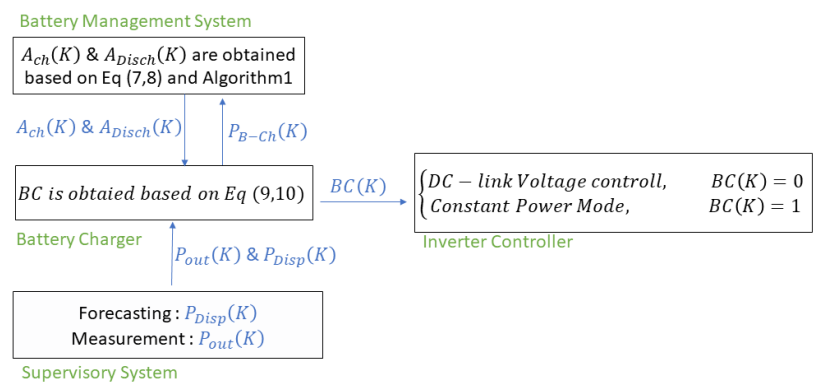

Fig. 3. The whole control system.

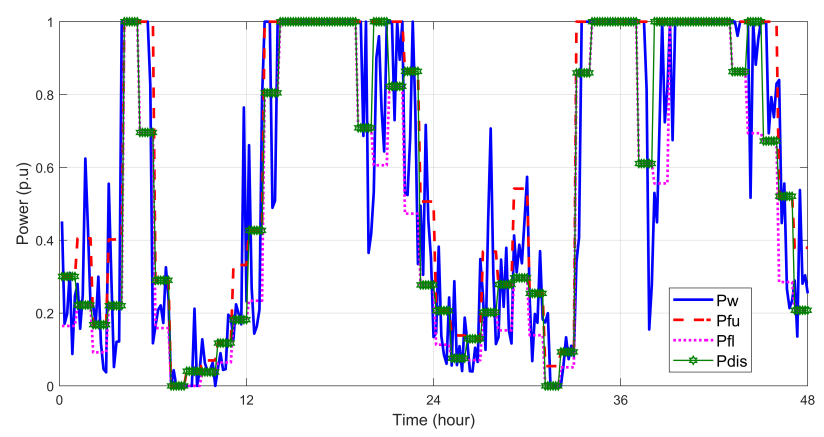

Fig. 4. Typical wind power, forecasted power, dispatched power.

The diagram of the whole control system is shown in the Fig. 4.

\section{CASE STUdY}

A hybrid wind-battery systems is simulated (Simulink/MATLAB) to achieve the power dispatching over 1-hour interval based on two methods; one-set battery and two-set battery models. A $2 \mathrm{MW}$ wind turbine is considered as the wind system. A given two-days wind power profile, and two forecasted profiles (Up: Pfu and Low: Pfl) considering \pm 10 prediction error ( [19]) are shown in Fig. 4 .Furthermore, the dispatched power based on (1) is obtained and shown in Fig. 4. Up and low predictive powers have been used to determine dispatching power one at a time in successive intervals. This is done to reduce the imbalance of battery power. Power dispatching is done using both models to compare their performance. We used the same battery capacity for both methods; $1 \mathrm{MWh}$ for the one-set model and $2 * 0.5 \mathrm{MWh}$ for the two-set model. Therefore, the battery cost is the same in both models. Comparison is done in terms of shallow and complete cycles, Number of charge/discharge
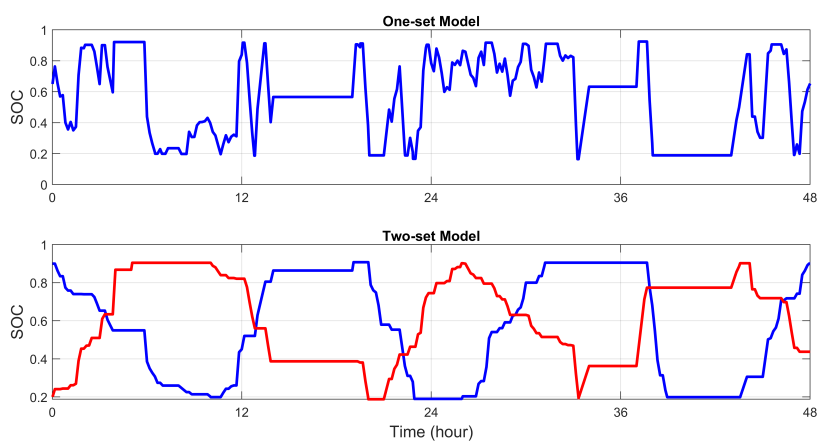

Fig. 5. SOC for one-set and proposed two-set models.

cycles, times of battery unavailability, and deviated energy from dispatched power. The simulation results for SOC are shown in Fig.5. As can been seen, the battery experiences many shallow and non-uniform cycles in the one-set model while in the two-set mode, it has a few complete and uniform cycles. The number of cycles during $48 \mathrm{~h}$ is shown in Table I, 28 cycles for the one-set model and just 3 cycles for the two-set model. Therefore, the battery has a very better performance in the proposed model which leads to a larger calendar lifetime. Furthermore, the status of availability of battery pack is compared in Fig. 6. As can be seen, the battery is more available in the proposed model as in the proposed model, the two batteries operate in two opposite directions and in many times provide both charge and discharge status. The sum of the total battery unavailability times is shown in Table I; $6.5 \mathrm{~h}$ for one-set and $4.5 \mathrm{~h}$ for the proposed model. Finally, the output power profile with the dispatched power for two models are shown in Fig. 7. As can be seen, the deviation power from the dispatched is less in the proposed model. Therefore, the wind farm owner will incur a lower penalty for power deviation. The amount of dispatched energy and deviated energy during $48 \mathrm{~h}$ are shown in Table I. As can be seen, for the same dispatched energy, the deviation energy is $1.5 \mathrm{MWh}$ and $0.6 \mathrm{MWh}$ for the one-set and proposed two-set models, respectively.

\section{CONCLUSIONS}

With the increasing influence of renewable resources in power systems, these resources should be able to participate in the dispatching and unit commitment programs, just like conventional generation units. Due to the oscillating nature and uncertainty of wind speed, the presence of fluctuations and prediction errors in wind power is inevitable. Hybrid wind- 
TABLE I

COMPARISON THE PERFORMANCE OF ONE-SET AND TWO-SET BATTERY MODEL OVER 48H .

\begin{tabular}{cccccc}
\hline & Battery Capacity & Number of cycles & Battery unavailability & Deviated Energy & Dispatched Energy \\
\hline One-set Model & $1 \mathrm{MWh}$ & 28 & $6.5 \mathrm{~h}$ & $1.5 \mathrm{MWh}$ & $27 \mathrm{MWh}$ \\
Two-set Model & $(2 * 0.5) \mathrm{MWh}$ & 3 & $4.5 \mathrm{~h}$ & $0.6 \mathrm{MWh}$ & $27 \mathrm{MWh}$ \\
\hline
\end{tabular}
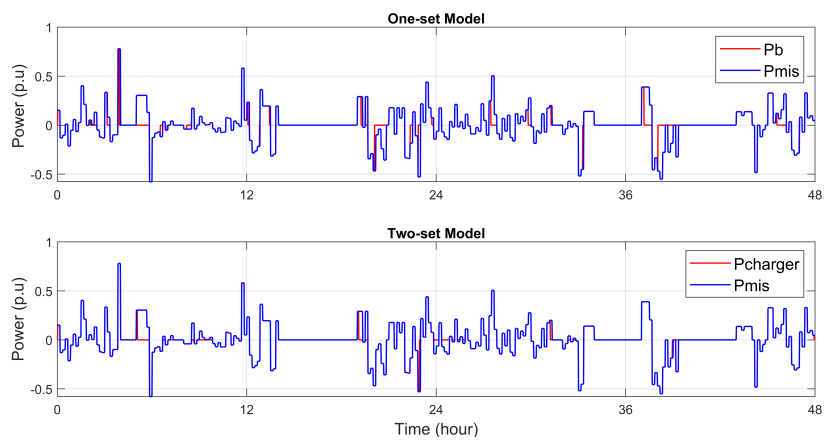

Fig. 6. Battery Availability in the one-set and proposed two-set models.

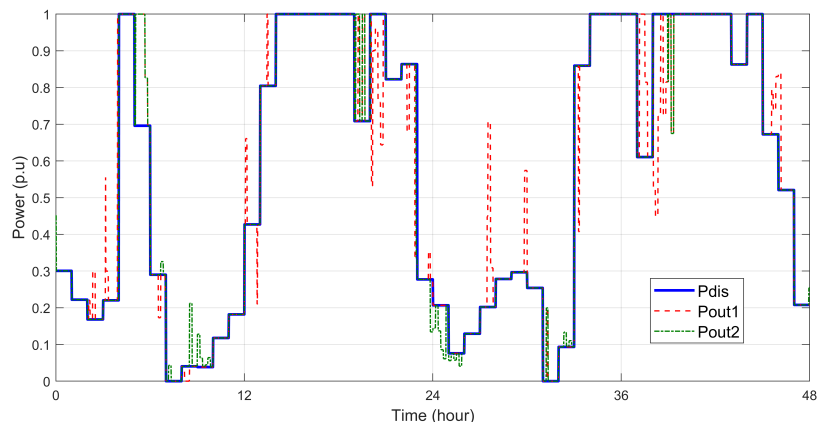

Fig. 7. The output power in the one-set and proposed two-set models.

battery systems is one of the most interesting solutions to compensate for power deviations. Among these, minimize the battery costs is the most important challenge. Due to high fluctuations in wind power, batteries must experience fast and incomplete charge/discharge cycles, which leads to reduced throughput and battery life. In this paper, to improve battery performance, an extended model of battery system with two separate sets is presented so that batteries can experience complete charge/discharge cycles. Also, a scenario is provided to coordinate and balance the two sets of batteries in the event of a prediction error so that the batteries always experience complete cycles and the availability is increased.

\section{REFERENCES}

[1] G. Buticchi, C.-S. Lam, X. Ruan, M. Liserre, D. Barater, M. Benbouzid, O. Gomis-Bellmunt, O. A. R. Paja, C. Kumar, R. Zhu, The role of renewable energy system in reshaping the electrical grid scenario, IEEE Open Journal of the Industrial Electronics Society (2021) 11doi:10.1109/OJIES.2021.3102860.

[2] T. Simla, W. Stanek, Influence of the wind energy sector on thermal power plants in the polish energy system, Renewable Energy 161 (2020) 928-938. doi:https://doi.org/10.1016/j.renene.2020.07.122.

[3] H. Huang, M. Zhou, S. Zhang, L. Zhang, G. Li, Y. Sun, Exploiting the operational flexibility of wind integrated hybrid ac/dc power systems, IEEE Transactions on Power Systems 36 (1) (2020) 818-826.
[4] N. Rezaei, M. Mazidi, M. Gholami, M. Mohiti, A new stochastic gain adaptive energy management system for smart microgrids considering frequency responsive loads, Energy Reports 6 (2020) 914-932.

[5] R. López-Rodríguez, A. Aguilera-González, I. Vechiu, S. Bacha, Dayahead mpc energy management system for an island wind/storage hybrid power plant, Energies 14 (4) (2021) 1066.

[6] S. Teleke, M. E. Baran, A. Q. Huang, S. Bhattacharya, L. Anderson, Control strategies for battery energy storage for wind farm dispatching, IEEE transactions on energy conversion 24 (3) (2009) 725-732.

[7] S. Majumder, S. A. Khaparde, A. P. Agalgaonkar, P. Ciufo, S. Perera, S. Kulkarni, Dft-based sizing of battery storage devices to determine day-ahead minimum variability injection dispatch with renewable energy resources, IEEE Transactions on Smart Grid 10 (1) (2017) 626-638.

[8] C.-L. Nguyen, H.-H. Lee, T.-W. Chun, Cost-optimized battery capacity and short-term power dispatch control for wind farm, IEEE Transactions on Industry Applications 51 (1) (2014) 595-606.

[9] L. Ye, C. Zhang, Y. Tang, W. Zhong, Y. Zhao, P. Lu, B. Zhai, H. Lan, Z. Li, Hierarchical model predictive control strategy based on dynamic active power dispatch for wind power cluster integration, in: 2020 IEEE Power Energy Society General Meeting (PESGM), 2020, pp. 1-1. doi:10.1109/PESGM41954.2020.9282123.

[10] A. Saez-de Ibarra, A. Milo, H. Gaztanaga, V. Debusschere, S. Bacha, Cooptimization of storage system sizing and control strategy for intelligent photovoltaic power plants market integration, IEEE Transactions on Sustainable Energy 7 (4) (2016) 1749-1761.

[11] M. Gholami, S. Fathi, J. Milimonfared, Z. Chen, F. Deng, The effect of turbulence and wake on the power fluctuation in the wind farms, in: 2017 Iranian Conference on Electrical Engineering (ICEE), IEEE, 2017, pp. $1148-1153$

[12] P. Roy, J. He, Y. Liao, Cost minimization of battery-supercapacitor hybrid energy storage for hourly dispatching wind-solar hybrid power system, IEEE Access 8 (2020) 210099-210115.

[13] A. Saez-de Ibarra, A. Milo, H. Gaztañaga, I. Etxeberria-Otadui, P. Rodríguez, S. Bacha, V. Debusschere, Analysis and comparison of battery energy storage technologies for grid applications, in: 2013 IEEE Grenoble Conference, IEEE, 2013, pp. 1-6.

[14] B. Hu, H. Nian, J. Yang, Y. Xu, H. Tong, L. Yang, A distributed energy storage system integrated in pmsg system for mitigating wind farm fluctuations and providing inertial response, in: 2021 4th International Conference on Energy, Electrical and Power Engineering (CEEPE), 2021, pp. 512-516. doi:10.1109/CEEPE51765.2021.9475691.

[15] A. K. Masih, H. Verma, Management of battery using ann controller for renewable hybrid system, in: 2021 2nd International Conference for Emerging Technology (INCET), 2021, pp. 1-6. doi:10.1109/INCET51464.2021.9456360.

[16] Z. Yang, L. Xia, X. Guan, Fluctuation reduction of wind power and sizing of battery energy storage systems in microgrids, IEEE Transactions on Automation Science and Engineering 17 (3) (2020) 1195-1207.

[17] S. Majumder, S. A. Khaparde, A. P. Agalgaonkar, P. Ciufo, S. Perera, S. Kulkarni, Dft-based sizing of battery storage devices to determine day-ahead minimum variability injection dispatch with renewable energy resources, IEEE Transactions on Smart Grid 10 (1) (2017) 626-638.

[18] M. Gholami, S. H. Fathi, J. Milimonfared, Z. Chen, F. Deng, A new strategy based on hybrid battery-wind power system for wind power dispatching, IET Generation, Transmission \& Distribution 12 (1) (2018) 160-169.

[19] J. Yan, K. Li, E.-W. Bai, J. Deng, A. M. Foley, Hybrid probabilistic wind power forecasting using temporally local gaussian process, IEEE Transactions on Sustainable Energy 7 (1) (2015) 87-95. 